\title{
ANALISIS FAKTOR-FAKTOR MOTIVASI WIRAUSAHA RUMAH MAKAN DI DESA MENDALO DARAT, KECAMATAN JAMBI LUAR KOTA KABUPATEN MUARO JAMBI
}

\author{
Dian Erika Candra \\ Program Studi Manajemen FEB Universitas Jambi \\ dianerika@gmail.com
}

\begin{abstract}
Abstrak
Tujuan penelitian ini adalah untuk menganalisis faktor-faktor motivasi wirausaha rumah makan dan untuk menganalisis faktor yang paling dominan dalam memotivasi wirausaha dalam usaha rumah makan di Desa Mendalo Darat, Kecamatan Jambi Luar Kota, Kabupaten Muaro Jambi. Jenis data ada dua yaitu data primer dan data sekunder. Data primer diperoleh dari pengumpuna data dengan cara penyebaran kuesioner, sedangkan data sekunder dati berbagai literature dan dokumen. Metode pengolahan data yang digunakan adalah analisis factor. Hasil penelitian menyimpulkan bahwa faktor motivasi wirausahan adalah : bantuan finansial, keinginan pribadi, pengetahuan teknis, mencari tantangan, status sosial dan faktor penggunaan dana tak terpakai. Adapun factor yang dominan adalah : berwirausaha karena ada dukungan finansial untuk mempermudah memulai usaha sendiri, berwirausaha karena keinginan pribadi, berwirausaha karena memiliki kemampuan dan pengetahuan teknis, berwirausaha karena ingin mencari tantangan dalam bekerja, berwirausaha karena ingin memperoleh status sosial pada Status sosial, berwirausaha adalah pilihan sendiri pada faktor keputusan.
\end{abstract}

Kata kunci : motivasi, wiraushaan, rumah makan

\begin{abstract}
The purpose of this study was to analyze the motivational factors of a restaurant entrepreneur and to analyze the most dominant factors in motivating entrepreneurs in a restaurant business in Mendalo Darat Village, Jambi Luar Kota District, Muaro Jambi Regency. There are two types of data, namely primary data and secondary data. Primary data obtained from data collection by distributing questionnaires, while secondary data from various literature and documents. The data processing method used is factor analysis. The results of the study concluded that the entrepreneurial motivational factors were: financial assistance, personal desires, technical knowledge, seeking challenges, social status and factors of the use of unused funds. The dominant factors are: entrepreneurship because there is financial support to make it easier to start their own business, entrepreneurship because of personal desires, entrepreneurship because they have the ability and technical knowledge, entrepreneurship because they want to find challenges in work, entrepreneurship because they want to obtain social status in social status, entrepreneurship is own choice of decision factors.
\end{abstract}

Keywords: motivation, entrepreneurship, restaurant

\section{PENDAHULUAN}

Pembangunan ekonomi daerah merupakan suatu proses dimana Pemerintah Daerah dan masyarakat mengelola sumberdaya-sumberdaya yang ada, dengan menjalin pola-pola kemitraan antara Pemerintah Daerah dan pihak swasta guna penciptaan 
lapangan kerja,peserta dapat merangsang pertumbuhan ekonomi di daerah bersangkutan (Suparmoko, 2002).

Keberhasilan pembangunan ekonomi daerah, sangat ditentukan oleh kebijakankebijakan pembangunan yang berlandaskan pada upaya meningkatkan pertumbuhan ekonomi yang mampu menciptakan lapangan kerja secara optimal dari segi jumlah, produktivitas dan efisien. Melihat terjadinya pergerakan peningkatan partisipasi angkatan kerja, maka perlu diketahui bagaimana kondisi tenaga kerja yang ada di Provinsi Jambi saat ini, baik yang mencakup jumlah persediaan tenaga kerja, kebutuhan tenaga kerja dan kesempatan kerja yang ada selain itu juga melihat bagaimana proyeksi tenaga kerja. Sementara pada kondisi saat ini besarnya jumlah persediaan tenaga kerja dan jumlah kesempatan kerja di Provinsi Jambi tidak seimbang (Junaidi dan Zulfanetti, 2016).

Hasil penelitian yang dilakukan Aggarwal, B. B., Kumar, A., \& Bharti, A. C. (2003), menemukan bahwa motivasi wirausaha ada dua kelompok faktor yaitu, motivasi internal dan eksternal. Faktor internal yakni keinginan untuk melakukan sesuatu yang baru, tingkat pendidikan partisipan, latar belakang pekerjaan. Sedangkan motivasi eksternal meliputi dukungan dan bantuan pemerintah, ketersediaan faktor produksi serta permintaan produk yang menjanjikan.

Pelaku wirausaha itu sendiri banyak yang berproduksi diberbagai bidang diantaranya di bidang jasa, kuliner, maupun dibidang produksi yang lainnya. Dari penelitian yang dilakukan di Desa Mendalo Darat Kecamatan Jambi Luar Kota Kabupaten Muaro Jambi terdapat wirausaha di bidang kuliner yang lebih mendominasi dari wirausaha yang lainnya, bisnis kuliner menjadi ladang bisnis yang menarik minat banyak orang. Hal ini disebabkan peluang bisnis pada sektor makanan lumayan menggiurkan. Selagi manusia masih membutuhkan makanan maka peluang bisnis di sektor makanan sangat terbuka. Dari penelitian di lapangan ditemukan terdapat 66 wirausaha yang berproduksi di bidang kuliner yaitu 26 wirausaha kuliner di kaki lima 5 wirausaha di bidang minuman dan 36 wirausaha di bidang kuliner wirausaha rumah makan.

Rumah makan lebih mendominasi dibandingkan dengan usaha lainnya, dari wawancara dengan beberapa wirausaha rumah makan, hasilnya ada berbagai macam jawaban dari pertanyaan apa yang memotivasi wirausaha lebih memilih bidang usaha rumah makan, hasilnya ada berbagai macam jawaban yang peneliti terima mulai dari faktor keinginan sendiri untuk memenuhi kebutuhan diri secara ekonomi, produksinya yang mudah, untuk meneruskan usaha keluarga dan ingin membantu keuangan di keluarga dan masih banyak jawaban yang peneliti terima.

Permasalahan dalam penelitian ini adalah faktor-faktor apa saja yang memotivasi wirausaha dalam usaha rumah makan di Desa Mendalo Darat Kecamatan Jambi Luar Kota Kabupaten Muaro Jambi dan faktor-faktor yang paling dominan dalam memotivasi wirausaha dalam usaha rumah makan di Desa Mendalo Darat Kecamatan Jambi Luar Kota Kabupaten Muaro Jambi.

\section{TINJAUAN PUSTAKA}

\section{Kewirausahaan}

Menurut Suryana (2013), kewirausahan muncul apabila seorang individu berani mengembangkan usaha-usaha dan ide-ide barunya. Proses kewirausahaan meliputi semua fungsi, aktivitas, dan tindakan yang berhubungan dengan perolehan peluang dan 
Seorang wirausahawan harus memiliki kemampuan yang kreatif dan inovatif dalam menemukan dan menciptakan berbagai ide. Setiap pikiran dan langkah wirausahawan adalah bisnis. Bahkan, mimpi seorang pebisnis sudah merupakan ide untuk berkreasi dalam menemukan dan menciptakan bisnis-bisnis baru (Kasmir, 2011).

Dalam menghadapi berbagai permasalahan, seorang wirausahawan senantiasa dituntut untuk kreatif. Dia mengetahui cara mencapai tujuan yang direncanakan, dan mampu berkonsentrasi serta berinisiatif memanfaatkan pengetahuan dan pengalaman untuk mengatur langkah sesuai dengan rencana yang telah dibuat menuju target (Machfoedz, Mas'ud, 2005).

\section{Motivasi}

Menurut Suryana, Yuyus dan Kartib Bayu (2011), motivasi merupakan kondisi psikologis yang mendasar, dan merupakan salah satu unsur yang dapat mencerminkan perilaku seseorang. Motivasi merupakan salah satu faktor penentu dalam pencapaian tujuan. Motivasi terletak dalam diri manusia dan tidak dapat dilihat dari luar. Motivasi mengarahkan manusia untuk melakukan perbuatan demi mencapai suatu tujuan tertentu (Mahesa, 2012). Menurut Robbins, Stephen P. (2001), motivasi sebagai kesediaan mengeluarkan tingkat upaya tinggi yang mengarah pada tujuan-tujuan organisasi, yang dikondisikan oleh kemampuan upaya tersebut untuk memenuhi suatu kebutuhan individual. Motivasi merupakan daya dorong untuk berusaha keras agar dapat mencapai tujuan tertentu, sesuai dengan kemampuan usahanya untuk memuaskan kebutuhan pribadi (Malinda, Maya, 2002)).

\section{Faktor-Faktor Motivasi Wirausaha}

Aggarwal, B. B., Kumar, A., \& Bharti, A. C. (2003), menemukan bahwa motivasi berwirausaha dari partisipan yang terlibat dalam penelitian mereka dapat dikelompokkan menjadi dua yaitu motivasi internal dan eksternal. Motivasi internal antara lain: keinginan untuk melakukan sesuatu yang baru; tingkat pendidikan partisipan; latar belakang; jumlah tahun pengalaman bekerja; dan latar belakang pekerjaan partisipan. Sedangkan motivasi eksternal meliputi: dukungan dan bantuan pemerintah; ketersediaan faktor produksi; serta permintaan produk yang menjanjikan.

Benzing, C., dan Chu, H.M., (2009), dalam studi mereka menemukan empat jenis motivasi berwirausaha antara lain:

1) Penghargaan ekstrinsik (extrinsic rewards), yaitu lebih merupakan alasan ekonomi yaitu keinginan seseorang untuk memperoleh pendapatan atau uang dalam jumlah yang lebih besar dibandingkan pendapatan yang diterima dari pekerjaan yang selama ini atau sudah dijalani sebelumnya..

2) Kebebasan atau otonomi (independence/autonomy), merujuk pada motivasi yang terkait dengan keinginan seorang wirausahawan untuk bebas menentukan usahanya.

3) Penghargaan intrinsik (intrinsic rewards), lebih terkait dengan pemenuhan diri dan pertumbuhan diri seseorang.

4) Keamanan Keluarga (family security), dimana motivasi untuk berwirausaha adalah terkait dengan kebutuhan akan rasa aman untuk keluarga.

\section{Rumah Makan}

Rumah makan atau sering disebut juga warung makan merupakan usaha skala mikro dan kecil yang menjual makanan. Rumah makan ini sering dikunjungi oleh orang kalangan menengah bawah, namun juga tidak menutup kemungkinan orang kalangan menengah atas juga sering mengunjunginya. Rumah makan memiliki pangsa pasar 
yang luas karena dapat mencakup semua kalangan. Menurut Ayodya, Wulan (2007), jenis-jenis usaha rumah makan dan skalanya adalah sebagai berikut:

1. Cafe: Merupakan rumah makan untuk segmen kelas menengah ke atas.

2. Restoran: Merupakan rumah makan untuk segmen kelas menengah dan bisa juga untuk kalangan atas.

3. Warung makan: Merupakan rumah makan kelas menengah ke bawah.

4. Kaki lima: Merupakan tempat makan yang jelas ditujukan untuk kelas ekonomi ke bawah.

\section{METODE PENELITIAN}

Junis penelitian yang digunakan dalam penelitian ini adalah penelitian diskriptif dengan metode kuantitatif dengan studi analisis faktor penggunaan kuesioner pengumpulan data.

Sumber data dalam penelitian ini berupa data primer dan data sekunder. Data Primer merupakan data yang di peroleh oleh penyebaran kuesioner kepada beberapa pelaku wirausaha yang membuka rumah makan di Desa Mendalo Darat Kecamatan Jambi Luar Kota Kabupaten Muaro Jambi. Data Sekunder dalam penelitian ini di peroleh dari berbagai bahan pustaka baik berupa buku-buku, jurnal, data-data elektronik yang di ambil dari internet, dan dokumen-dokumen pendukung lainnya yang berkitan dengan wirausaha yang membuka rumah makan .

Menurut Sugiyono (2011), populasi adalah wilayah generalisasi yang terdiri atas obyek/subyek yang mempunyai kualitas dan karakteristik tertentu yang ditetapkan oleh peneliti untuk dipelajari dan kemudian ditarik kesimpulannya. Populasi dari penelitian ini meliputi rumah makan yang berada di Desa Mendalo Darat Kecamatan Jambi Luar Kota Kabupaten Muaro Jambi yang berjumlah 36 rumah makan.

Metode pengumpulan data yang digunakan dalam penelitian ini adalah penelitian kepustakaan (library research) dan penelitian lapangan (field research). Uji instrument yang dilakukan adalah uji validitas dan uji reliabilitas. Metode Analisis yang digunakan adalah analisis faktor untuk menjawab rumusan masalah pertama dan kedua yaitu untuk mengetahui faktor faktor yang memotivasi wirausaha rumah makan dan dari faktor-faktor tersebut akan diperoleh faktor yang paling dominan yang memotivasi wirausaha rumah makan.

Analisis faktor merupakan salah satu bentuk analisis multivariat yang tujuan umumnya adalah menemukan satu atau beberapa variable atau konsep yang diyakini sebagai sumber yang melandasi seperangkat variabel nyata (Maholtra, Naresh K., 2007). Analisis faktor bertujuan menemukan hubungan (interrelationship) antara sejumlah variabel-variabel yang saling independen satu dengan yang lainnya, sehingga bisa dibuat satu atau beberapa kumpulan variabel yang lebih sedikit dari jumlah variabel awal (Santoso, Singgih, 2010). Pada dasarnya terdapat dua jenis analisis faktor yaitu Exploratory Factor Analysisi (EFA), dan Confirmatory Factor Analysis Analysis (CFA).

\section{HASIL DAN PEMBAHASAN Instrumen Penelitian}

Uji validitas terhadap sampel sebanyak $(n)=36$ dan besarnya df dapat dihitung 36-2 $=34$, dengan $\mathrm{df}=34$ dan alpha 0,05 di dapat $r$ tabel $=0.3291$. $r$ hitung lebih besar dari $\mathrm{r}$ tabel dan nilai positif, maka butir atau pertanyaan atau indicator tersebut dinyatakan valid (Ghozali, Imam, 2011). Keseluruhan indikator penelitian dinyatakan 
valid karena $r$ hitung yang dapat dilihat dari hasil statistic Corrected ItemTotal Correlation lebih besar dari $r$ tabel ( $r$ hitung $>r$ tabel).

Berdasarkan hasil uji reliabilitas yang dilakukan dapat disimpulkan bahwa keseluruhan indicator penelitian dinyatakan reliable karena memiliki nilai cronbach alpha $0.796>0,70$.

\section{Deskripsi Variabel Penelitian}

Berikut daftar rekapitulasi tanggapan responden mengenai faktor-faktor yang memotivasi wirausaha rumah makan yang ada di Desa Mendalo Darat Kecamatan Jambi Luar Kota Kabupaten Muaro Jambi.

\section{Tabel 1. Rekapitulasi Tanggapan Responden}

\begin{tabular}{|c|c|c|c|}
\hline No & Pernyataan & Jumlah & Presentase \\
\hline 1. & $\begin{array}{l}\text { Mempermudah memulai usaha sendiri apa bila ada dukungan } \\
\text { finansial }\end{array}$ & 158 & $14.5 \%$ \\
\hline 2. & Berwirausaha karena termotivasi dengan orang lain & 135 & $17 \%$ \\
\hline 3. & Berwirausaha karena menyukai tantangan dalam bekerja & 126 & $18.2 \%$ \\
\hline 4. & Berwirausaha karena ada paksaan dari orang lain & 201 & $11.4 \%$ \\
\hline 5. & $\begin{array}{l}\text { Berwirausaha karena menyukai pekerjaan yang keterlibatan } \\
\text { dalam keseluruhan proses kegiatan }\end{array}$ & 130 & $17.7 \%$ \\
\hline 6. & Untuk meningkatkan pendapatan & 135 & $17 \%$ \\
\hline 7. & $\begin{array}{l}\text { Berwirausaha adalah salah satu cara untuk memiliki peluang } \\
\text { secara ekonomis }\end{array}$ & 124 & $18.5 \%$ \\
\hline 8. & Berwirausaha untuk mengalihkan dana yang tidak terpakai & 125 & $18.4 \%$ \\
\hline 9. & $\begin{array}{l}\text { Berwirausaha karena menginginkan pekerjaan yang dapat } \\
\text { memanfaatkan daya kreativitas }\end{array}$ & 141 & $16.3 \%$ \\
\hline 10. & $\begin{array}{l}\text { Berwirausaha adalah salah satu cara untuk dapat merealisasikan } \\
\text { kemampuan diri }\end{array}$ & 150 & $15.3 \%$ \\
\hline 11. & Berwirausaha adalah pilihan sendiri & 161 & $14.3 \%$ \\
\hline 12. & Berwirausaha karena tidak bekerja & 136 & $16.9 \%$ \\
\hline 13. & $\begin{array}{l}\text { Keluarga terdekat saya mengganggap bahwa menjadi seorang } \\
\text { wirausaha adalah keputusan yang tepat }\end{array}$ & 145 & $15.8 \%$ \\
\hline 14. & Berwirausaha untuk membantu prekonomian keluarga & 149 & $15.4 \%$ \\
\hline 15. & Berwirausaha karena dorongan keluarga & 147 & $15.6 \%$ \\
\hline 16. & Berwirausaha karena ingin memperoleh status sosial & 138 & $16.6 \%$ \\
\hline \multicolumn{3}{|c|}{ Rata-rata } & $258.9 \%$ \\
\hline
\end{tabular}

(Sumber: hasil rekapitulasi data)

Berdasarkan Tabel 1 menggambarkan tanggapan responden mengenai 16 Indikator yang memotivasi wirausaha rumah makan. Berdasarkan hasil pengolahan data yang disajikan pada tabel diatas, dapat dilihat bahwa pernyataan 7 " Berwirausaha adalah salah satu cara untuk memiliki peluang secara ekonomis" mendapatkan presentase skor total teringgi yaitu sebesar $18.5 \%$ sedangkan pernyataan 4 " Berwirausaha karena ada paksaan dari orang lain " mendapatkan presentase skor total terendah yaitu $11.4 \%$.

\section{Analisis Faktor}

\section{Uji Asumsi Analisis Faktor}

Sesuai dengan landasan teori, ada dua hal yang perlu dilakukan agar analisis faktor dapat dilaksanakan, yang pertama yaitu menentukan besaran nilai Barlett Test Of Sphericity, yang digunakan untuk mengetahui apakah ada korelasi yang dignifikan antar variable, dan kedua adalah Keiser-Meyers-Olkin (KMO) kecukupan sampel 
dangan cara membandingkan besarnya koefisien korelasi yang diamati dengan koefisien korelasi parsialnya. Kecukupan data atau sample dapat diidentifikasi mellaui Measure of Sampling Adequacy (MSA) dan Kaiser-Meyer-Olkin (KMO). Nilai kedua ukuran tersebut bias didapatkan dengan bantuan software SPSS. Mengacu pada landasan teeori bahwa sekelompok data dikatakan memenuhi asumsi kecukupan data adalah jika nilai MSA dan KMO lebih besar daripada 0,5. Berikut ini adalah output nilai MSA dan KMO dari SPSS.

Tabel 2. Uji KMO dan Bartlett ${ }^{\text {ee }}$ s test

KMO and Bartlett's Test

\begin{tabular}{llr}
\hline Kaiser-Meyer-Olkin Measure of Sampling Adequacy. & .541 \\
\hline Bartlett's Test of Sphericity & Approx. Chi-Square & 217.014 \\
\cline { 2 - 3 } & df & 120 \\
\cline { 2 - 3 } & Sig. & .000 \\
\hline
\end{tabular}

Sumber: Hasil Olahan SPSS 25

Hasil Uji KMO dan Bartlettes test menunjukkan KMO MSA lebih dari 0,50 yaitu 0,541 dan nilai Bartlettes s test dengan Chi-Square $=217.014$ dan signifikan pada 0.000. nilai menunjukkan bahwa penelitian ini diperbolehkan menggunakan analisis faktor sebagai metode analisisnya karena nilai yang dihasilkan diatas lebih dari 0,5. Dengan hasil diatas, maka dapat dikatakan bahwa variabel dan sampel digunakan memungkinkan untuk dilakukan analisis lebih lanjut.

\section{Penentuan banyak faktor dengan eigenvalue}

Nilai Eigenvalue adalah sebuah nilai yang merepresentasikan keseluruhan varian yang dijelaskan oleh masing-masing faktor, Seperti yang dijelaskan diatas penemuan banyak faktor didasarkan pada nilai eigenvalue dari matriks korelasi antar variable. Hasil perhitungan pada tahap ini disajikan pada tabel berikut ini.

Tabel 3. Matriks Korelasi antar Tabel Total Variance Explained

\begin{tabular}{|c|c|c|c|c|c|c|c|c|c|}
\hline \multirow[b]{2}{*}{$\begin{array}{l}\text { Compo } \\
\text { nent }\end{array}$} & \multicolumn{3}{|c|}{ Initial Eigenvalues } & \multicolumn{3}{|c|}{$\begin{array}{l}\text { Extraction Sums of Squared } \\
\text { Loadings }\end{array}$} & \multicolumn{3}{|c|}{$\begin{array}{c}\text { Rotation Sums of Squared } \\
\text { Loadings }\end{array}$} \\
\hline & Total & $\begin{array}{c}\% \text { of } \\
\text { Variance }\end{array}$ & $\underset{\%}{\text { Cumulative }}$ & Total & $\begin{array}{c}\% \text { of } \\
\text { Variance }\end{array}$ & $\begin{array}{c}\text { Cumulative } \\
\%\end{array}$ & Total & $\begin{array}{c}\% \text { of } \\
\text { Variance }\end{array}$ & $\underset{\%}{\text { Cumulative }}$ \\
\hline 1 & 4.440 & 27.747 & 27.747 & 4.440 & 27.747 & 27.747 & 2.633 & 16.454 & 16.454 \\
\hline 2 & 2.094 & 13.088 & 40.835 & 2.094 & 13.088 & 40.835 & 2.221 & 13.883 & 30.337 \\
\hline 3 & 1.672 & 10.451 & 51.286 & 1.672 & 10.451 & 51.286 & 2.083 & 13.017 & 43.354 \\
\hline 4 & 1.406 & 8.789 & 60.075 & 1.406 & 8.789 & 60.075 & 1.980 & 12.374 & 55.728 \\
\hline 5 & 1.111 & 6.945 & 67.020 & 1.111 & 6.945 & 67.020 & 1.620 & 10.126 & 65.854 \\
\hline 6 & 1.062 & 6.635 & 73.654 & 1.062 & 6.635 & 73.654 & 1.248 & 7.800 & 73.654 \\
\hline 7 & .820 & 5.128 & 78.782 & & & & & & \\
\hline 8 & .705 & 4.408 & 83.190 & & & & & & \\
\hline 9 & .613 & 3.829 & 87.019 & & & & & & \\
\hline 10 & .543 & 3.395 & 90.414 & & & & & & \\
\hline 11 & .483 & 3.018 & 93.433 & & & & & & \\
\hline 12 & .350 & 2.188 & 95.620 & & & & & & \\
\hline 13 & .275 & 1.717 & 97.337 & & & & & & \\
\hline 14 & .196 & 1.228 & 98.565 & & & & & & \\
\hline 15 & .151 & .942 & 99.507 & & & & & & \\
\hline 16 & .079 & .493 & 100.000 & & & & & & \\
\hline
\end{tabular}

Extraction Method: Principal Component Analysis.

Sumber: Hasil Olahan Spss Versi 25 
Berdasarkan tabel 3 output total variance explained pada bagian "initial eigenvalues" , maka ada 6 ( enam) faktor yang dapat terbentuk dari 16 varian yang dianalisis. Dimana syaratnya untuk menjadi sebuah faktor, maka nilai eigenvalue harus lebih besar dari 1 , dimana :

- Nilai Eigentvalue Component 1 sebesar 4.440 atau > 1 maka menjadi faktor 1 dan mampu menjelaskan $27.747 \%$ variasi;

- Nilai Eigentvalue Component 2 sebesar 2.094 atau > 1 maka menjadi faktor 2 dan mampu menjelaskan $13.088 \%$ variasi;

- Nilai Eigentvalue Component 3 sebesar 1.672 atau > 1 maka menjadi faktor 3 dan mampu menjelaskan $10.451 \%$ variasi;

- Nilai Eigentvalue Component 4 sebesar 1.406 atau > 1 maka menjadi faktor 4 dan mampu menjelaskan $8.789 \%$ variasi;

- Nilai Eigentvalue Component 5 sebesar 1.111 atau > 1 maka menjadi faktor 5 dan mampu menjelaskan $6.945 \%$ variasi;

- Nilai Eigentvalue Component 6 sebesar 1.062 atau > 1 maka menjadi faktor 6 dan mampu menjelaskan $6.635 \%$ variasi;

\section{Penentuan banyak faktor dengan Scree Plot}

Scree plot adalah grafik yang menggambarkan plot nilai eigenvalue dari masing-masing variable. Dibawah ini adalah output scree plot dari SPSS.

\section{Gambar 1. Scree Plot}

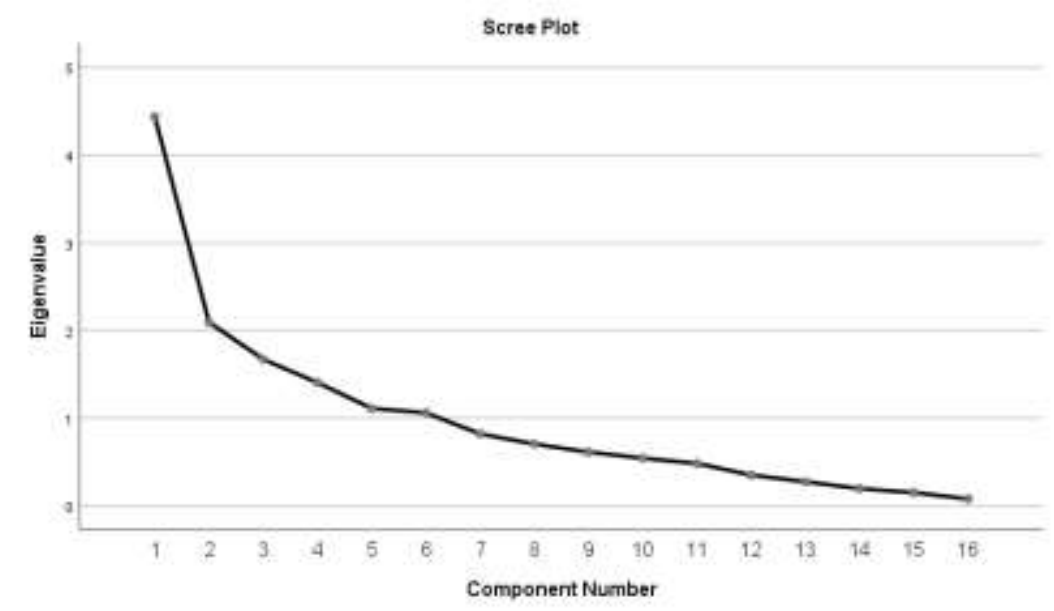

Sumber : Hasil Olahan Spss Versi 25

Scree plot adalah salah satu alternatif yang dapat digunakan untuk membantu penelitian menentukan berapa banyak faktor terbentuk yang dapat mewakili keragaman perubahan-perubahan asal atau perhitungan faktor.

Seperti pada pembahasan sebelumnya, untuk menentukan banyak faktor yang terbentuk dapat dilihat pada nilai eigenvalue yang lebih dari satu. Pada gambar 1, dapat dilihat bahwa terdapat 6 komponen yaitu faktor 1 , faktor 2 , faktor 3 , faktor 4 , faktor 5 , dan faktor 6 , yang mempunyai nilai eigenvalue lebih dari satu, jadi ada 6 faktor yang terbentuk.

\section{Pengelompokan variabel kedalam faktor-faktor}

Pada software SPSS metode ektraksi yang digunakan untuk pembagian variable adalah principal component factoring analysis. Pembagian variable-variabel ke dalam 
kelompok faktor tertentu didasarkan pada perbandingan nilai loading faktor secara mutlak mana yang lebih besar antar loading factor dari faktor-faktor tersebut. Tabel dibawah ini merupakan output SPSS yang telah melalui proses rotasi variamax.

Tabel 4. Pengelompokan Variabel kedalam Faktor

\begin{tabular}{|c|c|c|c|c|c|c|}
\hline Variabel & $\begin{array}{l}\text { Fak- } \\
\text { tor } 1\end{array}$ & $\begin{array}{l}\text { Fak- } \\
\text { tor } 2\end{array}$ & $\begin{array}{l}\text { Fak- } \\
\text { tor } 3\end{array}$ & $\begin{array}{l}\text { Fak- } \\
\text { tor } 4\end{array}$ & $\begin{array}{l}\text { Fak- } \\
\text { tor } 5\end{array}$ & $\begin{array}{l}\text { Fak- } \\
\text { tor } 6\end{array}$ \\
\hline $\begin{array}{l}\text { - Mempermudah memulai usaha sendiri apa bila ada } \\
\text { dukungan finansial }\end{array}$ & 0.772 & & & & & \\
\hline - Berwirausaha karena menyukai pekerjaan yang & 0.753 & & & & & \\
\hline keterlibatan dalam keseluruhan proses kegiatan & 0.637 & & & & & \\
\hline $\begin{array}{l}\text { - Untuk meningkatkan pendapatan } \\
\text { - Berwirausaha karena termotivasi dengan orang lain }\end{array}$ & 0.610 & & & & & \\
\hline $\begin{array}{l}\text { - Berwirausaha adalah salah satu cara untuk memiliki } \\
\text { peluang secara ekonomis }\end{array}$ & 0.516 & & & & & \\
\hline - Berwirausaha adalah pilihan sendiri & & 0.918 & & & & \\
\hline $\begin{array}{l}\text { - Keluarga terdekat saya mengganggap bahwa menjadi } \\
\text { seorang wirausaha adalah keputusan yang tepat }\end{array}$ & & 0.765 & & & & \\
\hline $\begin{array}{l}\text { - Berwirausaha adalah salah satu cara untuk dapat } \\
\text { merealisasikan kemampuan diri }\end{array}$ & & & 0.799 & & & \\
\hline $\begin{array}{l}\text { - Berwirausaha karena menyukai tantangan dalam } \\
\text { bekeria }\end{array}$ & & & 0.763 & & & \\
\hline $\begin{array}{l}\text { - Berwirausaha untuk membantu prekonomian } \\
\text { keluarga }\end{array}$ & & & 0.691 & & & \\
\hline $\begin{array}{l}\text { - Berwirausaha karena menginginkan pekerjaan yang } \\
\text { dapat memanfaatkan daya kreativitas }\end{array}$ & & & & 0.824 & & \\
\hline - Berwirausaha karena dorongan keluarga & & & & 0.715 & & \\
\hline - Berwirausaha karena ingin memperoleh status sosial & & & & & 0.729 & \\
\hline - Berwirausaha karena ada paksaan dari orang lain & & & & & 0.646 & \\
\hline $\begin{array}{l}\text { - Berwirausaha untuk mengalihkan dana yang tidak } \\
\text { terpakai }\end{array}$ & & & & & & 0.867 \\
\hline
\end{tabular}

Seperti dapat dilihat pada tabel 4 maka dapat disimpulkan bahwa faktor 1 hingga faktor 6 telah mempunyai anggota variabelnya masing-masing sesuai dengan nilai loading faktor-nya. Kemudian setelah dilakukan pengelompokan variable kedalam faktor.

\section{Penamaan Faktor}

Pemberian nama faktor merupakan ketentuan dari peneliti, pemberian nama tersebut berdasarkan variabel yang dapat diukur langsung untuk menggambarkan faktor yang merupakan variabel yang tidak dapat diukur secara langsung. Pemberian nama faktor dari hasil pengelompokan variabel disajikan pada tabel 5 berikut ini. Peneliti memberikan label untuk variabel motivasi untuk mempersingkat dan memudahkan dalam mengingat variabel motivasi dalam penelitian ini. 
Tabel 5. Penamaan Faktor

\begin{tabular}{ll}
\hline \multicolumn{1}{c}{ Variabel } & \multicolumn{1}{c}{ Nama Faktor } \\
\hline $\begin{array}{l}\text { Mempermudah memulai usaha sendiri apa bila ada dukungan } \\
\text { Berwirausaha karena menyukai pekerjaan yang keterlibatan } \\
\text { dalam keseluruhan proses kegiatan }\end{array}$ & $\begin{array}{c}\text { Bantuan Finansial (Finansial } \\
\text { Assistance }\end{array}$ \\
$\begin{array}{l}\text { Untuk meningkatkan pendapatan } \\
\text { Berwirausaha karena termotivasi dengan orang lain } \\
\text { Berwirausaha adalah salah satu cara untuk memiliki peluang } \\
\text { secara ekonomis }\end{array}$ & \\
\hline $\begin{array}{l}\text { Berwirausaha adalah pilihan sendiri } \\
\text { Keluarga terdekat saya mengganggap bahwa menjadi seorang } \\
\text { wirausaha adalah keputusan yang tepat }\end{array}$ & \\
\hline $\begin{array}{l}\text { Berwirausaha adalah salah satu cara untuk dapat } \\
\text { merealisasikan kemampuan diri }\end{array}$ & \\
$\begin{array}{l}\text { Berwirausaha karena menyukai tantangan dalam bekerja } \\
\text { Berwirausaha untuk membantu prekonomian keluarga }\end{array}$ & Knowledge) \\
\hline $\begin{array}{l}\text { Berwirausaha karena menginginkan pekerjaan yang dapat } \\
\text { memanfaatkan daya kreativitas }\end{array}$ & $\begin{array}{l}\text { Mencari tantangan (Seeking } \\
\text { Berwirausaha karena dorongan keluarga }\end{array}$ \\
\hline $\begin{array}{l}\text { Berwirausaha karena ingin memperoleh status sosial } \\
\text { Berwirausaha karena ada paksaan dari orang lain }\end{array}$ & Status Sosial (Social Social) \\
\hline Berwirausaha untuk mengalihkan dana yang tidak terpakai & Faktor Penggunaan dana tak \\
& terpakai (Use of idle Funds Factor) \\
\hline
\end{tabular}

Pemberian nama faktor motivasi Bantuan Finansial (Finansial Assistance), Keinginan pribadi (Self Interest), Pengetahuan Teknis (Technical Knowledge), Mencari tantangan (Seeking Chanllange), Status Sosial (Social Social) dan Faktor Penggunaan dana tak terpakai (Use of idle Funds Factor) berdasarkan pada faktor hasil penelitian Jesurajan, S. Vargheese Antony \& M. Edwin Gnanadhas (2011).

\section{SIMPULAN DAN SARAN}

Faktor-faktor motivasi wirausaha rumah makan di desa mendalo jambi adalah Bantuan Finansial (Finansial Assistance), Keinginan pribadi (Self Interest), Pengetahuan Teknis (Technical Knowledge), Mencari tantangan (Seeking Chanllange), Status Sosial (Social Social) dan Faktor Penggunaan dana tak terpakai (Use of idle Funds Factor).

Variabel yang paling dominan pada masing-masing faktor yaitu : Berwirausaha karena ada dukungan finansial untuk mempermudah memulai usaha sendiri (Finansial Assistance), Berwirausaha karena keinginan pribadi (Self Interest), Berwirausaha karena memiliki kemampuan dan pengetahuan teknis (Technical Knowledge), Berwirausaha karena ingin mencari tantangan dalam bekerja (Seeking Chanllange), Berwirausaha karena ingin memperoleh status sosial pada Status Sosial (Social Factor) dan berwirausaha adalah pilihan sendiri pada Faktor Keputusan (Decision Factor).

Saran bagi wirausaha rumah makan diharapkan pada bantuan finansial keluarga dapat membantu dalam hal permodalan sehingga nantinya usaha tersebut bisa menjadi usaha yang mencakup milik keluarga dan dapat memberikan lapangan pekerjaan untuk saudara terdekat, pada faktor keinginan pribadi lebih dimantapkan, mencari informasi tentang kewirausahaan dan menambahkan pengalaman dibidang serta memilihi modal sebagai bekal untuk memulai usaha, pada faktor kemampuan teknis mendalami lebih 
lanjut tentang kemampuan yang dimiliki sehingga nantinya jika sudah memulai usaha kemampuan tersebut dapat bermanfaat di proses usaha

Bagi para peneliti selanjutnya untuk dapat menambah dan memperluas variabelvariabel tidak hanya di variabel Mandiri Secara Ekonomi (economic Independence) Mencari tantangan (Seeking Chanllange),Keinginan Keluarga (Family Members Interest), Status Sosial (Social Factor), Penggunaan Dana Tidak Terpakai (Use of Idle Funds), dan Faktor Keputusan (Decision Factor) serta dapat melakukan penelitian pada subyek yang berbeda seperti dibidang produksi, tenaga kerja dan lain-lain.

\section{DAFTAR PUSTAKA}

Aggarwal, B. B., Kumar, A., \& Bharti, A. C. (2003). Anticancer potential of curcumin: preclinical and clinical studies. Anticancer research, 23(1/A), 363-398.

Ayodya, Wulan (2007). Kursus Singkat Usaha Rumah Makan Laris Manis. Jakarta: PT Elex Media Komputindo.

Benzing, C., dan Chu, H.M., (2009). A comparison of the motivations of small business owners in Africa. Journal Small Business and Enterprise Development, 16 (1), pp. 60-77.

Ghozali, Imam (2011). Aplikasi Analisis Multivariate Dengan Program IBM SPSS. Badan Penerbit Univeristas Diopnegoro: Semarang.

Junaidi dan Zulfanetti (2016). Analisis Kondisi dan Proyeksi Ketenagakerjaan di Provinsi Jambi.

Jesurajan, S. Vargheese Antony \& M. Edwin Gnanadhas (2011). A Study On The Factors Motivating Women To Become Entrepreneurs in Tirunelveli District. Asian Journal of Business and Economics.

Kasmir (2011). Analisis Laporan Keuangan, Rajawali Pers, Jakarta.

Malinda, Maya. (2002). Faktor-Faktor Yang Mempengaruhi Seseorang Berwirausaha. Jurnal Manajemen Maranatha. Vol 1: hal 105-117.

Maholtra, Naresh K. (2007). Marketng Research an Applied Orientation, 5th ed, New Jersey: Prentice Hall.

Machfoedz, Mas'ud (2005). Kewirausahaan : metode, manajemen, dan implementasi, Yogyakarta : BPFE.

Robbins, Stephen P. (2001). Perilaku Organisasi. Jakarta: Pearson Education Asia dan PT Prenhallindo.

Suparmoko (2002), Ekonpmi publik: untuk keuangan dan pembangunan daerah, Universitas negeri malang

Suryana (2013). Kewirausahaan Kiat dan Proses Menuju Sukses. Jakarta: Salemba Empat.

Suryana, Yuyus dan Kartib Bayu (2011). Kewirausahaan: Pendekatan Karakteristik Wirausahawan Sukses. Jakarta: Kencana.

Sugiyono (2011). Metode Penelitian Kuantitatif, Kualitatif dan R\&D. Bandung:Afabeta Santoso, Singgih (2010). Statistik Multivariat : Konsep dan Aplikasi dengan SPSS. Jakarta: PT Elex Media Komputindo 